\title{
REFERENCIA FANTÁSTICA Y LITERATURA DE TRANSGRESIÓN
}

\author{
Javier Rodrígue\% Pequeño \\ Universidad Autónoma de Madrid
}

La definición y delimitación de la literatura fantástica es un problemal que ha merecido la atención de la Teoría y la Crítica literarias, sobre todo descle la clécalla de los sesenta de muestro) siglo, aunc|ue la introducción de los conceptos «fantasía» e «imaginación», tantas veces erróncamente considerados sinónimos', correspondió a la Teoría literaria romántica, encargada de la sustitución del espejo por la lámpara. F.l paso de la representación objetiva a expresión de sentimientos subjetivos, en clelinitiva, provoca la consicleración de la representación no mimética con la literatura? 2

En punto a la literatura fantástica, en el sentido al que nosotros aludimos cuando hacemos referencia a la distinción entre el modelo de munclo real y el modelo de mundo fantástico, separados por la transgresión ", los críticos discrepan incluso en su origen. Para Fimilio

1.- Véase Antonio García Berrio, «La Teoría litcraria romántica: lamtasía e imaginatción en la construc-

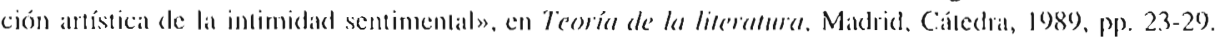

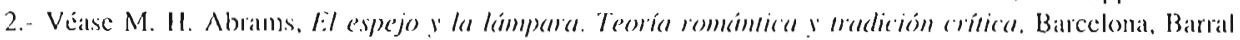

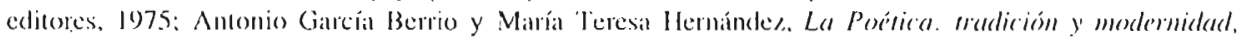
Madricl. Síntesis, 1988. pl). 32 y ss.; Rene Wellek. Ilistoria de la critica moderna, vol. II, Madrid, Cite(los, I969).

3.- Para todo lo concemiente a lat teoría de los mundos posibles, consúltese la obra de Tomás Albalade-

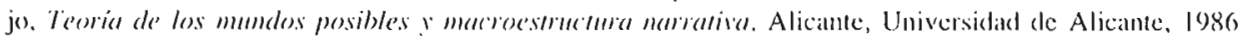

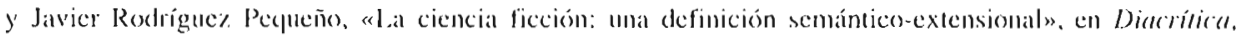
n." 5. 1990, pp. 53-78, donde nosotros mismos hemos realizado una ampliación de los lipos de modelo de mundo, introduciendo el tipo de lo lantástico verosímil. tipo no mimélico pero verosímil. 


\section{JAVIER RODRÍ(GUHZL PLQUEÑO)}

Carilla lo fantástico aparece en la literatura universal en el mismo momento de la aparición de ésta, en la que sin ducla estaba presente lo asombroso, lo sobrenatural y lo maravilloso! Al leer esta afimación, immediatamente pensamos en los mitos, en lass leyendas, en las sagas, en los cuentos de Las mil y uma noches y en tantas formas literarias de tradición oral. Bioy Casares, aunque reconoce los antiquísimos orígenes de lass que él llama «ficciones fantásticas», considera que "como género definido, la litcratura fantástica no aparece hasta el sigko XIX, y en lengua inglesa» ${ }^{5}$. Para Antonio Risco los orígenes de esta literatura están apuntat dos en el Barroco, épocia de profundas transformaciones sociales y culturales. alcanzando su plenitud, paralelamente a la literatura realista, en los siglos XIX y XX". Esic autor explica el tardío nacimiento del género por la tradicional represión a la que fue sometida la fantasía, considerada peligrosa por su difícil control. Sin embargo, surgían obras fantásticas, aunque en ellas se imponía el final feliz, edilicante y aleccionaclor, o, en cualcyuicr caso, su amenaza era eliminada, al menos se intentaba, calfificando esta literatura como arte de evasión, banal'.

Tanto Cristina Risco Salanova ${ }^{*}$ como María Teresal Ramos cstán convencidas de que el género fantástico nace en el siglo XVIII, en el que el racionalismo y las creencias irracionales conviven al tiempo que se rechazan mutuamente, pues su concepción de la realidad es opuesta, resultado la segunda corriente de una reacción contra la visión científica y determinista de la primera".

Para Roger Caillois, lo fantástico hace su aparición tras el triunfo ede la concepción científica de un orden racional y necesario de los fenómenos, después del reconocimiento de un determinismo estricto en el enciadenamiento de las causas y los cfectos. Lin unia paliabra. nace en el momento en que cada uno está más o menos persuadido de la imposibiliclatcl de los milagros»". Nace, en definitiva, para este autor. en el primer tercio del siglo $X \mid X$, cuando Poe, Gogol, Hoffmann, Maturín, Hawthone, Meriméc y otros escriben sus oblas macstras"

Por nuestra parte. crecmos que el siglo XIX es efectivimente el siglo de oro de lat literatura fantástica, aunque no podemos olvidar ni a Honacio Walpole ni a Julio (ortixar, por cilar dos brillantes ejemplos. uno anterior y oro posterior. (ompartimos la opinión de familio Carilla y consideramos que la literatura fambístical nace al mismo tiempo yue la literalura. ya sea de transmisión oral o escriti.

La esencia de lo fantástico en lo no pertenceciente a mestro munclo. Io irreal. o. comos

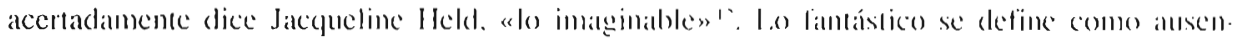

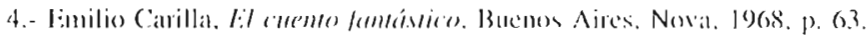

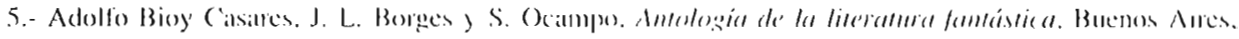
1:(l. Sudamericina, 1()$+()$

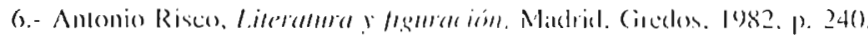

7.- Hiclem. p. 232.

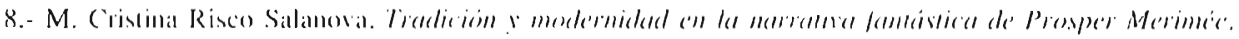
Vallaklolid. Tesis Doctoral. Iogs'. p. 8.5.

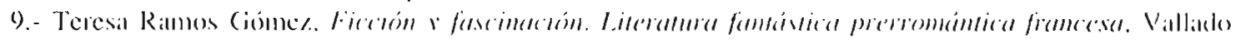
licl, Servicio ele P'ubliciaciontes, 1988, p. 42.

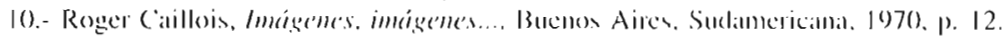

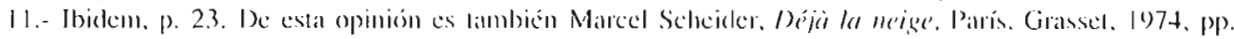
9-11. donde manifiestal (que lo lantístico viempre nos lleval de lo conocielo a lo desconocido y se mantifiesa como irrupcion de lo intacional en el uniserse racional.

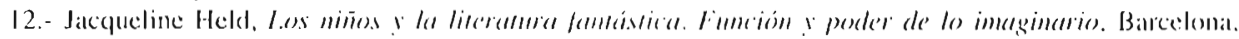
Paicks. 1987. 


\section{RFFFRENCIA I:AN'TÁSIICA Y I.ITERATURA DE TRANSGRESIÓN}

cia de realidad; es lo que no existe, lo que no es, lo irreal. Fn términos generales esta definición podría ser sufieicnle, pero en el ámbito literario es parcial, puesto (que la fieción se define también por su no existencia. Ianto lo fiecional como lo fantástico pertenecen a lo no real, pero lo fantástico exige una condición más: la transgresión de las leyes del munclo real objetivo. Por consiguiente, Io fantástico es siempre liccional, auncue no toda ficción es fanlástica, o lo que és lo mismo, lo fantistico es una sección de la fïcción determinada por la infracción. por la ruptura, por la transgresión. En este senticlo se manifiesta lréne Béssière, para quien lo lantástico es uno de los caminos de la imaginación en el que se construye un mundo diferente al real efectivo, aunque se haga por medio de pensamientos, palabras y realidades del mundo real objetivo ${ }^{1.4}$. De la teoría sobre lo tantástico de esta autora destacamos su idea de que lo lantástico se especilica por lo inverosímil, pero no únicamente, y su convicción de que no existe un lenguaje fantástico ni lo fantástico como género literario. Wilhelm Dilthey abunda en este aspecto cuando dice que la fantasía es la expresión de una especial concepeión del mundo que sólo puede comunicarse gracias a los medios de expresión verbalit.

Louis Vax considera el miedo como el factor calracterístico de lo que se ha llamado "género fantástico», y afirma que el arte fantístico introluce obligatoriamente terroles imaginarios en el seno del mundo real"s. De la misma opinión es H. P I ovecraft, para quien "la atmósfera es lo más importante pues el criterio definitivo de la autenticidad de lo fantástico no es la estructura de la intriga, sino la creación de una impresión específica (...). Por este motivo (lebemos juzgar el cuento fantástico no tanto por las intenciones del alutor y los mecamismos de la intriga, como en función de la intensidad emocional que provoca. (...) Un cuento es fantástico simplentente si el lector experimenta profundamente una sensación de temor y de terror, la presencia de mundos y (le fuerzas insólitass 'n. Seggún este criterio, toda la literatura fantástica se caracteriza por el horros que provoca en el lector, dejando fuera de este tipo de literatura un anyplio repertorio de obras que, tansgrediendo las leyes del mundo empírico, no provocan, ni lo persiguen, el miedo del lector. El mismo criterio manejan Roger Caillois y Peter Penzoldt, si bien distinguen lo fantástico de lo maravilloso. Penzoldt asegura que la literatura fantástica, excepción hecha de los cuentos de hadas. es litcratura de terror, son historias que nos hacen pensar si la fieción que percibimos como lal no es, después de todo, la realidad ". Ambos tienen una concepeión terrorífica de lo fantástico, en la gue hay, como en la de Scheider, irrupción de lo sobrenatural $\mathrm{en}$ el mundo real ${ }^{1 x}$, intrusión del misterio en la vida colidiana "1". Vemos, pues, que ni Vax, ni L,ovecraft ni Penzoldt consideran fantástico acpello que no es capaz de generar miedo u horror. I as hadas buenas, los genios, los duendes, las innumerables aventuras y lugares creados por lolkien, Fnde, elc., no pertenece-

13.- Cfi. Tréne Bessière, l.e récil fumkássique. París, Larousse, 1974. pp. 10-11.

14.- Willelm Dilahey, Literanma ý fameasia. México. Fondo de Cullura Ficonómica, 1978.

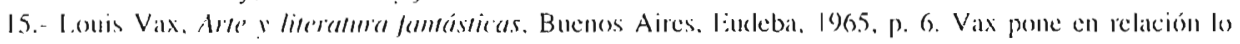
fantístico con lo imposible, y dice que la imposibiliclad realizada pierele su carbicter lantístico, pues dejal (le ser imposible (p. 31). Creemos que aciental al constaltar la exislencia de obras fantásticas cómicals, trágicas, elegíacis..., y al alimar que lo fantástico se opone esencialmente a lo real. Sin embargo, Vax se enciarga más de las formals de lo fantístice y de sus formas vecinas que de su esencia.

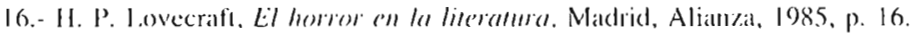

17.- Peler Penzolde. The Supermanaral in Fiction. Nueva York. Humanities Press. 1965. p. 9.

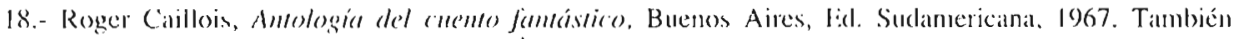

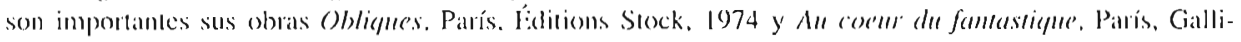
mard. 1965.

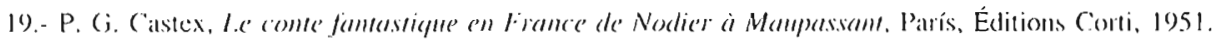


rían al modelo de mundo fantástico en este sistema teórico, pues «no trastoman nuestra seguridad 20. Para estos autores existen tres niveles distintos: Io maravilloso, lo fantístico y lo real, conceptos que intenta explicar Roger Caillois:

fil universo de lo maravilloso está naturalmente poblado de dragones, de unicornios y de hadas; los milagros y las metamorfosis son allí continuos; la varita mágica, (le uso corriente; los calismanes, los genios, los elfos, los animales agradecidos abundan; las madrinas, en el acto, colnan los deseos de las huérfanas meritorias... En lo fantástico, al contrario, lo sobrenatural aparece como una ruptura de la colerencia universal. lil prodigio se vuelve allí una agresión prohibida, amenazadora, que quiebra la estabilidad de un mundo en el cual las leyes hasta entonces cran tenidas por rigurosas e inmutables. Fis lo imposible, sobreviniendo de improviso en un mundo de donde lo imposible cstá desterrado por definición".

Y propone como distintivo de lo lantástico «la impresión de extrañèa irreductible»"2. Caillois introluce un criterio nuevo, la ruptura del orden natural del mundo, que se produce en lo fantástico y no en lo maravilloso, donde eel espanto que proviene de la violación de las leyes natturales no tiene ningún lugar»"?

Fstamos, por tamto, ante lo lantístico como el tipo de literatura que manifiesta una quiebra de la coherencia del universo, quiebra producida por la imsupción insólita de lo extranatulal en el mundo cotidiano ". Frente a lo fantástico se sitúa el universo maravilloso. un mundo sin rupturas, sin confrontaciones sicuiera, un mundo en el (que sus componentes no causan ningún micdo, únicamente sorpresa amable, que además concluye felizmente ${ }^{25}$.

Lals definiciones de lo fantástico yue hemos revisadto hasta ahora se basan, unas en la capacidad de producir miedo en el lector, otras en ese mismo temor pero producido por la ruptura, por la transgresión de las leyes del mundor real efectivo. Hay quienes abandonam el criterio del terror para definir lo fantástico, considerando al género una transgresión de la realidad (ue presenta to inexplicable y lo contradictorio de ésta; de este modo el orden del mundo es puesto en entredicho por un fenómeno, por un acontecimiento que se sale de las reglats del juego.

Analicemos las hipótesis que consideran el miedo como criterio definitorio. La primera objeción radica. en opinión de 'T. Todorov, en cue «si la sensación de temor debe encontrarse en el lector, habría que deducir (...) que el género de una obra depende de la sangre fría de su lector»"20. Tampoco sirve buscar la sensación de miedo en los personajes. Por un lado, los cuentos de hadas - a los que estos autores, por considerarlos maravillosos, oponen lo fantástico- pueden ser historials de terror (los Cuentos de Perrault, por ejemplo); por otra

20.- Louis Vax, Arte y literanura fantásticas, cit. . p. 10.

21.- Roger Caillosis, Imaigenes, imágene's..., cit. . p. 11.

22.- Ibidem, p. 30.

23.- Ibiciem. p. 21.

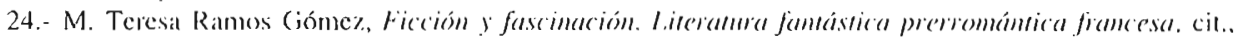
p. 42 .

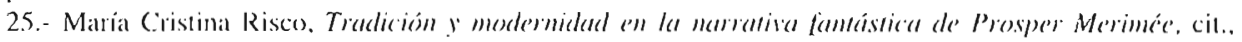
p. 85. Paara esta autora. igualmente, la literatura fantística supone ecl quebrantamiento, la transgresión de un orden nalural, social o moral» (ibidem, p. 92).

26.- Tzvetan Todorov, Innodncrion a la literanura fantástica, Buenos Aires. Tiempo Contemporáneo. 1972, p. 46. 


\section{RLEERRENCIA FANTÁSTIC A Y L.ITERATURA DE TRANSGRESIÓN}

partc, hay relatos fantásticos en los que el terror está totalmente ausente 27. Tampoco Jacepueline licld considera en absoluto que lo fantástico sea sinónimo de angustioso y ascgura que el relato de angustia y de horror no constituye sino una de las formas posibles de lo fantástico literario ${ }^{2 x}$. De este criterio participa también Harry Belevan, pues, según él, considerar cl miedo lo definitorio de lo fantástico equivale a contundir un síntoma cualquicra con el suceso del cual es sólo un indicio "2". En nuestra opinión, el temor se relaciona a menudo con lo fantástico, pero no es una condición necesaria "); el miedo y lo fantástico pueden coincidir, manifestarse simultáneamente, pero no de modo necesario, nunca en una relación (le dependencia, pues ni lo fantástico provoca siempre miedo ni el mico produce lo fantástico. la literatura de terror no es más que uno de los diversos géneros de la literatura lantástica, y no exclusivamente de ésta, pues podemos encontrar obras de terror cuyas estructuras de conjunto referencial siguen reglas propias de modelo de mundo ficcional verosímil, por tanto, pertenecientes al macromodelo de mundo real. Muchos autores suclen incurrir en el error de considerar obras fantásticas los relatos de terror y los policíacos en los que aparecen motivos que, efectivamente, provocin el escalofrío del lector, pero que finalmente son esclarecidos por la razón, sin hallarse en ellos ningún motivo para adscribirlos a ninguno de los dos tipos de modelo de mundo fantástico." Todorov incluye estas obras dentro de lo pue él denomina lantástico extraño", aunque como veremos más adelante, no estamos de acuer(o con la clasificiación de este crílico.

En cuanto a los estudiosos que distinguen lo fantástico gracias a la transgresión que produce terror - grupo en el que clebemos incluir a Jaime Alaraki, quien cree que "lo fantástico, al negar o contradecir momentáneamente la gramálica que gobierna la realidad, produce un estremecimiento, un escalofío o un horror»"3 pensamos que no loda transgresión produce terror (buena parte de la obra de Cortáar, Borges, Poe e incluso Kalka, universalmente admiticlos como maestros (lel género fantástico, corrobora nuestra afirmación) y que en lo maravilloso también se produce una ruptura del orden natural: iacaso no hay ruptura y transgresión en Perer Pan y. Wendy de James M. Barrice?

Todorov, en su excelente trabajo publicado en 1970, definc lo fantástico como la vacilación ante lo irracional:

Lin un mundo que es el nuestro, el que conocenos, sin diablos, sílfides, ni vampiros se produce un acontecimiento imposible de explicar por las leyes de ese mismo mun(o) familiar. El que percibe el acontecimiento debe optar por una de las dos solucio-

\section{7. - Ibidem.}

28.- Jacqueline Held, los niños y la literamara fantassica. Funcion y. poder de lo imaginario. cil.. pp. 14 y ss.

29.- Harry Belevan, Teoría de lo funtástico, Barcelona, Anagrama, 1976, p. 79.

30.- Tzvetan Todorov, Introducción a la literanura fancística, cit., p. 47.

31. - Nos referimos a la división que establecimos en nuestro artículo anteriomente citado. Distinguimos dos macromodelos de mundos, el real y el fantístico, separaclos por la transgresión de las reglas del mundo real efectivo. Dentro del macromodelo de mundo real están el tipo I, el de lo verdadero, y el tipo Il de modelo de mundo, el de lo fiecional verosímil; pertenecen al macromodelo de mundo fantístico los tipos III y IV de modelo de mundo, el de lo fantástico verosímil y el de lo fantástico inverosímil respectivamente. Esta división está basada en la fijaça por Tomás Albadalejo y únicamente difiere en la inclusión de un nuevo tipo de modelo de mundo, el de lo fantástico verosímil.

32.- T. Todorov, Introducción a la literamera fantástica. cit., p. 57.

33.- Jaime Alarraki, En busca del unicornio: Ios cueness de Julio Cortazar. Elementos para una poélica de lo neofantástico, Madrid, Gredos, 1983, p. 33. 
nes: o bien se trata de una ilusión de los sentidos. de un producto de la imaginación. $y$ las leyes del munde siguen siendo lo yue son, o bien el acontecimiento se produjo realmente. es parte integrante de la realidad, y entonces esta mismal realidad está regida por leves cpue desconocemos (...) Lo fantístico ocupal el tiempo de esal incertidumbre. En cuanto se elige una de las des propuestiss. se deja el terreno de lo lantástico para entrar en un género vecino: lo extraño o lo maravilloso. L.o fantástico es la vacilación experimentadla por un ser que no conoce mas que las leyes maturales, frente a unt acontecimiento aparentemente sobrenatural".

la vacilación de la (jue habla Todorov es en principio del personaje, pero mís adelante retoma este aspecto y asegura que lo fantástico implica una integración del lector con el munde de los personajes ${ }^{k s}$. La incertidumbre no afecta sólo al personaje, sino también. y principalmente, al lector. o, más exactamente, al narratario, como asegura Roberto Reis". F́ste es el mosivo de la crítical que Anazildo Vasconcelos da Silva hace de la resis de Toudorov. a quien acusa de basar lo fantástico en la relación del texto con el lector, criterio que oscila del lector al personaje, pues el primero ha de «sulirir» como el segundo ${ }^{77}$. Fin términos de Martíne\% Bonati. podríamos cifrar el error del búlgaro en centrar lo fantástico en la comunicación y no en lo comunicado ${ }^{\text {?x }}$, en atender a un criterio pragmático en lugar de a uno semántico.

Palla Todorov lo fantístico ache cumplir tres condiciones. En primer lugar. el texto tiene que obligar al lector a considerar el mundo de los personajes como un mundo de personajes reales y vacilar entre una explicación natural y unia explicación sobrenatural de los aconlecimientos evocallos. I uego, esta vacilación puecle ser senticla lambién por un personaje. Fänalmente es imprescindible que el lector adopte una determinadia actitud frente al texto: deberá rechazar tanto la interpretación alegórica como la interpretación poética. I a primera y la tercera condiciones son indispensables en los textos lantásticos; la segundla puede no cumplirse"." Ciertamente, Todorov apunta con tino a lo que es la imprescindible situación del lector en la esfera col la cue el productor se ha colocado y ha colocado sul obra. Sin cmbargo, nos sorprende gue Todorov. el mismo que rechaza por subjetiva la capacidad de sentir terror del lector como rasgo distintivo del género, conceda ahora al mismo lector el papel capital en la esencial de lo fantístico.

Lis digno de destacar de este trabajo de Todorov la subdivision que realizal de lo lantástico. () lo que él Ilama "géneros vecinos». Si la vacilación no dura más que un momento, dice, Io fantástico es tremendamente efímero, y aunque aquélla sea prolongadla. Lo fantástico sicmpre desemboca en otra categoría. Como veíamos anteriormente, el papel del lector es en este punto definitivo para delimitar no sólo lo lantástico sino sus géneros vecinos. De este modo, si el lector decide que las leyes de la realidad quedan intactas y permiten explicar los fenómenos descritos, dice cute la obra pertenece a «lo extraño». Si decide (jue es necesario admitir nuevas leyes de la naturateza mediante las cuales el fenómeno puede ser cxplicado.

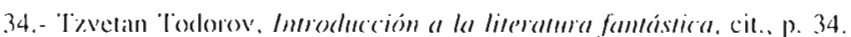

3.5.- Ibidem, P. 41.

36.- Véase Roberto Reis, "Para Uma Detinição Do Fantistico", en ('hasqui, VI, 3. 1977, pp. 37-43. p. 38.

37. - Anazilde Vasconcelos da Silva. "A lógica da ambiguiidacle fantástica", en Rerista de Lelras T. A., 11." 2, 1975. p). 43-48, p. 44.

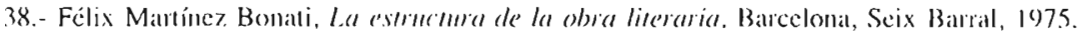

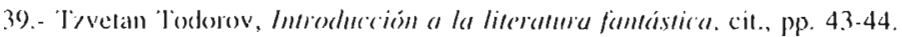




\section{RIII:EIRIENCIA I'ANTÁSTICA Y LITERATURA DE TRANSGRESIÓN}

entramos en el terreno de "lo maravilloso»" Por consiguiente, lo fantístico, más que un género, es el límite entre dos géneros. Io extraño y lo maravilloso. Fstos géneros forman una oposición tripartita en la que lo fantástico puro seria el cje. el presente. Lo maravilloso corresponde a un fenóneno desconocido, aún no visto, por venir, al futuro. Fn lo extraño, en cambio, to inexplicable es reducido a hechos conocidos a una experiencia previa, al pasado. Cada uno de estos géneros vecinos presental un subgénero transitorio que se caracteriza porque, auncue mantiene (lurante largo tiempo la vacilación, acaba linalmente en lo maravilloso o en lo extraño. Fstas subdivisiones las representa Todorov de la siguiente manera:

\begin{tabular}{|c|c|c|c|}
\hline extraño & fantástico & fantástico & maravilloso \\
puros & extraño & maravilloso & puros \\
\hline
\end{tabular}

Lo fantístico puro está representado por la línea media gue separa lo fantástico-extraño de lo fantístico-maravilloso. I.o fantástico-extraño son los acontecimientos (jue a lo largo del relato parecen sobrenaturales pero gue. finalmente, reciben una explicación racional. La vacilación del personaje y del leckor se mamtiene durante largo tiempo gracials al carácter insólito de los acontecimientos cpue hace creer a ambos que presencian hechos sobrenaturales. A lo extraño puro pertenecen lass obras (fue relatan acontecimientos explicables perlectamente por lass leyes de la razón. pero gue son, de una u otra mancra, incrébles. extraordinarios, y por este motivo provocan en el personaje y en ei lector una reacción similar a la cue producen los textos lantásticos. Con respecto a eslas calegorías o subgéneros debemos hateer una objeción: si los acontecimientos son perfectamente explicables por la razón y por leyes del mun(to real objetivo, no podemos hablar de subgéneros del género fantástico, puesto gue no aceplamos la reacción del lector o la del personaje como definitoria del género y menos aún la reacción de éstos en un momento de la obra, pues su reacción final en el caso de lo lanlástico-extraño podría ighlalmente ser contemplada, o la reacción del lector o del personaje con la visión global de la obra. Para nosotros el criterio válido es la transgresión de las leyes del mundo real efectivo, objetive o empírico porque en definitiva es la que gobierna, por medio de las reglas que rigen las distintas estructuras de conjunto referencial, la obra de arte verbal.

Pertenecen a lo fantástico-malavilloso todos los relatos que se presentan como fantásticos y que finalmente teminan con la aceplación de lo sobsenatural. Estos relatos son, para Todorov, los gue más se acercinn a lo fintástico puro, pues por el hecho mismo de no dar explicación racional nos sugieren la existencia de lo sobrenatural. Existe finalmente lo maravilloso-puro, género en el cual los elementos sobrenaturales no provocan ningunia réacción particular ni en los personajes ni en el lector. La característica de lo maravilloso no es la actitud hacia los acontecimientos relatados sino la naturaleza misma de esos acontecimicntos" $\Lambda$ esta división cabe objetar, aclemás, guc Toclorov cambia el critcrio distintivo: unas veces utiliza la reacción tanto dél lector como de los personajes y otras la naturalezal de los acontecimientos. con lo cual no ofrece, a nuestro juicio, una solución válicla.

No obstante, Todorov rompe con la tradición al no identificar lo maravilloso con el

4().- Ibidem, p. 53.

41.- Ibidem. pp. 56-68. En las páginas siguientes habla de otros subgéneros como lo maravilloso-hiperbólico, lo maravilloso-exótico, lo maravilloso-instrumental y lo maravilloso-científico, que, sin embargo. ofrecen menos interés. salvo por su oposición, porque encuentran explicación, al lo maravilloso-pure. 
cuento de hadas, siendo éste en realidad "una de las variedades de lo maravillosom»". La tesis de Toclorov es sin duda la más difundida y, aunque nosotros mostremos aquí nuestro desacuerdo en varios apartados, no se puede olvidar el avance que su estudio supuso en este campos?

Creemos que la confusión de algunos críticos nace de una concepción tripartita de mundos: el real, el fantástico y el maravilloso. Nosotros, siguicndo la Teoría de los mundos posibles de Tomás Albaladejo, observamos únicamente dos modelos generales de mundo, el real y el lantástico. Fl modelo de mundo real es el empírico, el goberinado por las leyes naturales. el regiclo por la razón; en oposición a él se encuentra el modelo de mundo fantástico, que se define precisamente por esta oposición, por la antítesis. $\mathrm{Nl}$ modelo de mundo lantástico pertenece lo sobrenatural, lo extraordinario, lo maravillosso, lo inexplicable; en delinitiva, lo que escapa a la explicación racional.

Para cue una obra sea fantástica no es necesario que nos presente todo un mundo fantástico conformado, con todos sus elementos; no es necesario tampoco que todos los elementos de esa obra pertenezcan al modelo de mundo fantástico. La presencia de un elemento extaño, malavilloso, sobrenatural adscribe la obra al género fantístico ${ }^{4.4}$. Ĺste es el caso de $l: l$ hombre imvisible de Herberl (j. Wells, de lrankenstein de Mary Shelley y de lil extraño caso del Dr. Jekyll y Mr Hyde de Stevenson, en los que lo fantástico es solamente un personaje, frente a El sernor de los anillos de Tolkien, la trilogía de La fimdación de Asimov y la hiscoria interminable de Linde, yue muestran un mundo distinto, con otras leyes.

Del mismo modo, conviene aclarar que el carácter poco probable de la acción o de los acontecimientos de una obra literaria, es decir, que sean hechos (pue normalmente no se dan en la realidad"s, no indica que esa obra pertenezcal a un modelo de mundo fantástico. Fis lo que Tomás Albaladejo agrupa bajo la denominación de fieciones realistas con bajo grado de verosimilitud th. Por otra parte, hay que tener en cuenta que ciertos elementos que hoy consideramos fantásticos eran tenidos en otras épocas por elementos pertenecientes al mundo real, a nuestro mundo, en cuyo caso su presencia en una obra no la convertía en lantásticat ${ }^{47}$, de la

42.- Ibidem, p. 68.

43.- Cfi. Elsal Dehennin, «De lo fambístico y su estrategia natratival”, en Iberorromamia, n." 19. 1984, pp. 53-65, para quien la teoría de Todorov es globalmente válisla y Ana M."Barrenecheal, "Ensayo de una tipología de la literatura fantístical», cit., quien disiente de la solución que se propone en Introducción " la literamra fantástica pero reconoce también sus méritos, como la distinción entre fantástico y alegórico y fantástico y poesía, basada en la distinta referencialidlad de ambals. ko que no significia que la poesía no tenga referente, sino que no se refiere a nada exterior a ella misma, no remite de las palabras a los hechos (véanse las páginas 74 y ss. de la obra citada de Todorov). Sí parece ciento que la poesia exige una valoración distinta, en la que conceptos tan importantes como lo imeal, to imposible, lo fantístico, adepuicren otra dimensión, y la verosinilitud es intranscendente, inclevante.

44.- Isto queda perfectamente regulado por la Ley de maximos semánticos y las restricciones a dichat ley, claboradas ambas por el profesor Albaladejo en sus obras Teoria de los mumdos posibles y macroes

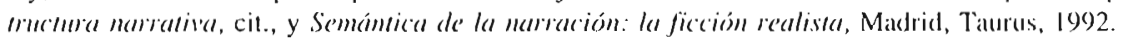

45.- Este tipo de acciones o acontecimientos se dan con bastante frecuencia en las obras de la llamada "literatura juvenil», generalmente de aventuras, del tipo de La isla del tesoro de Stevenson o la villela al munde en 80 días de Verne.

46.- C.fr. Tonaís Allsaladejo, Semántica de la narracionn: la ficción realista, cit.

47.- Estamos pensando, por ejemplo, en la concepción que de Dios, Ios ángeles, el demonio, los milagros... se tenía en la Fedad Media. Al analizar una obra medieval, o de cualquicr ofla épocal, hemos de tener en cuenta la mentalidad de entonces, su contexto en todos los sentidos. 


\section{RLILLRIENCIA FANTÁSTICA Y IITTERATURA DF: TRANSGRESIÓN}

misma forma que en otros tiempos consicleraban sobrenaturales ciertos hechos como las tormentas, los rayos, ete. que hoy son perfectamente razomables y aceptados como tales en nuestro mundo.

No aceptamos una oposición tripartita de modelos de mundo sino una oposición dual que enfienta lo real a lo fantástico. En este sistema, lo maravilloso es una parte de lo fantástico (pue no pocos identifican eon las naraciones an ables con final leliz, los relatos donde las hadas son generosas, donde los duendes tienen buenos instintos..., narraciones destinatas a un público supuestanente infamtil. En cualquier caso, es incongrtente oponerlo a lo fantáslico, pues forma parte de ello. Lo maravilloso ocupa un lugar en lo fantástico y está en oposición al mundo real, (lel que se dilerencia por lo mismo que el lantástico, esto es, por la transgresión ${ }^{-1 \mathrm{x}}$

Para nosotros, la naturalera fantástica de una obra le es conferida por la inclusión en su macroestructura de unos elementos del relerente que suponen una ruptura de las reglas del mundo real objetivo, de muestro mundo. Ana M." Barrenechea define la literatura fantástica como aquella que presenta, en forma de problema, hechos a-normales, a-maturales o irreales que suponen una visbación de mestro orden, elel orelen que llamamos natural o lógico, y por tanto originan un conflicto entre uno y otro orden dentro del texto, bien sea de forma explícita o implícita ". Dice Rosalba Campra:

Se puede alirmar que no existe lo lantástico sin la presencia de una lramsgresión: sca a nivel semántico, como superación de límites entre dos órdenes dados como incomunicables: sea a nivel sintáctico, como ruptura o calrencia de funciones en sentido extenso; sea a nivel verbal, como negación de la transparencia del lenguajeso.

Fin el plano semántico, Campra propone como estructuración gencral del texto fantástico la definición de una esfera $A$ totalmente independiente de una esfera $B$ y sin posibles puntos de contacto entre ellas; con una motivación o sin ella se produce una superposición que lleva a $A$ y a $B$ a coincidir parcial o totalmente, de manera thansitoria o definitiva"s. Fin esta mis-

48.- Palla completal el pantrama de lo fanlístico, véase Ana M.+ Barrenechea y Susana Speralli Piñeiro, La literamara fantistica argentina, México, Pondo de Cullura Económica. 1957: (ieorges Jacyuemin, Lit-

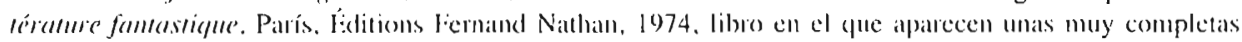
referencials a otras obrals sobre el mismo tema, y Jean Bellemin-Noël, "Notes sur le fantastique. Textes

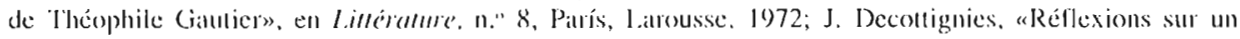
genre appelé 'fantastique's, en Le réel a le texke, París, Colin, 1974: Ana Cionzález Salvador. Conrinui-

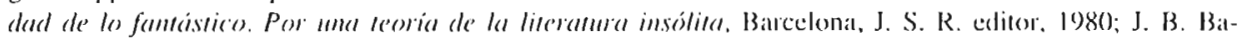

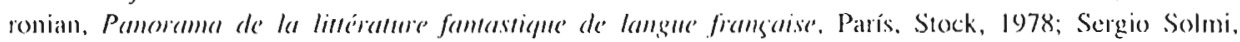

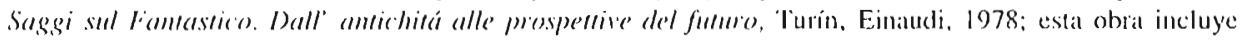
varios trabajos sobre las distintas formas de la literattra lantástica. Para el tema que nos ocupa, véase es-

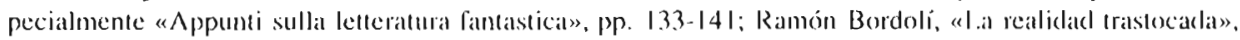

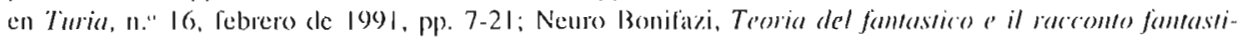
(o) in Italia. Ravenna. I ongo Islitore, 1982: Christine Brooke-Rose, A Rhetoric of Umreal. Canbridge. Cambridge University Press, 1981: Filipe Hurtado, A comstrusan de famlastico ma narrativa, I isboa, Ho-

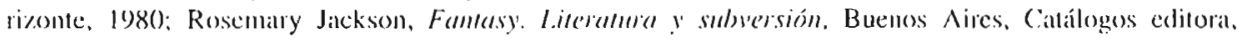
1986; Antonio Risco, Literatura y famtasía, Madrid, Taumts, 1982; Antonio Risco, Literatma fantástica de lengua española. Mardrid, Taurus, 1987.

49.- Ana M." Barrenechea, "Ensilyo de uma tipología de la literatura fantástica», cit., p. 395.

50.- Rosalla Campra, "Il fantastico: una isotopia della ransgressione», en Strumenti Critici, n." 4.5. 1981, pp. 199-231, p. 226.

51.- Ibidem, p. 208. Roberto Reis manifiesta una concepción de lo fantástico muy parecida: el producto 


\section{JAVII:R RODRÍGUEZ PEQUIIÑO}

ma línca que entiende lo famtástico como una dualidad problemática de planos se sitúan también Roberto Reis, Arturo A. Fox y I.ucila lnés Menar? quienes no difieren en lo esencial de la opinión de Ana M." Barrenecheal.

I a imnovacion de Campra radica en (pue. segán ella, lo fantístico puede lograrse gracias a la transgresión sinfáclica, mediante cierto lipo de rupturas en la organización de unos conenidos no necesaliamente fantásticos; con estals rupturas se crean mos vacíos yue se convierten en el espacio de ma posible distorsión de lo real ${ }^{3}$. l o fimtástico actual descansa. en

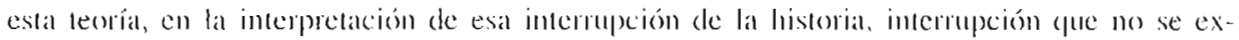
plicará, como en el relato policial, y a dilerencia de lo fantástico lradicional. (pue se explical parcialmente. Esta lesis esta muy cerca de las lecturas que el lector hace de las zonats de in-

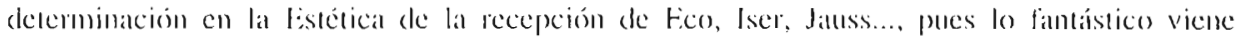
deleminate por un (liscurso interumpide e inexplicalo, el cual recibirá una interpreatción por parte det lector. Fsta interpretacion puede ser lantástica o no. elependiendo de la explicatción que calda lector dé a ese vacío. Fes cierlo que ma zona de insteterminación puede hacer (que alguicon alscriba ma obral al género fintástico, pero creemos (fue es un error desplazal la

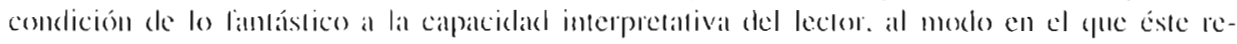
comstruya el segmeme omiticlo. inexplicardo. de forma yue para mos lectores lal obra entraba dentro del ámbito de la literatura fantástica y paral onos no.

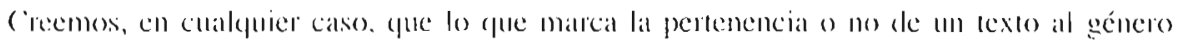
fimtástico es la relación de su estructura de comjumto referencial eon la realidad empricica. más exactamente si los seres, objelos. acciones, estades, procesos, idean... de alpuélla lransgreelen las leyes (lel mundo real objelivo. poreue incluso en el caso, admisible, de (ue la irresoluble filta de nexos, ente distimtos elementos de lo real sea la base de lo fantístico en el sentido de (jue sin esa zona de indeterminación nunca aparecería lo fantástico en la mente del lector. fo (jue hace este lector para comsiderar lantástica esa obra es incorporal a la primitiva estruclura de conjunto relerencial seres, objetos, ideas, procesos, acciones..., que la completan, (le lal modo (que, ahorat en la meval y mós amplia estructura de comjunto referencial. existe algén elemento (jue mamsgrede las leyes del mumboreal.

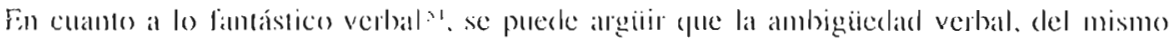
modo que la ambigiedad sintáctical. puede destruir lo lantástico. pues al existir más de una interprelación cabe la posibilidad de que el lector "lea» como lantástica esa oscuridad verbal al haclo de una lectura "realistal" de la misma.

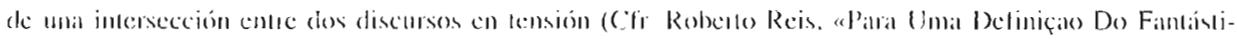

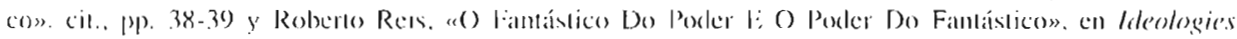
(and Literullere. III, 13. 1980). pp. 3-22).

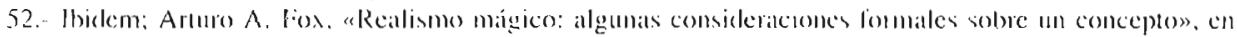

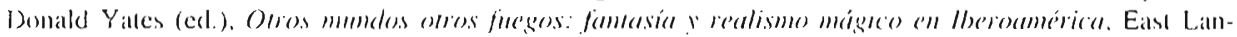

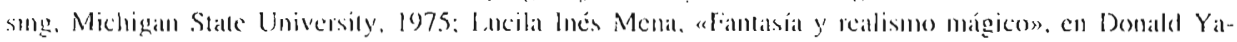

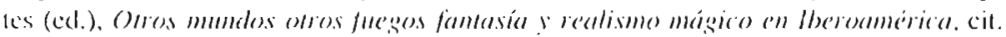

53.- Rosalba (ampra, "Fantástico y sintaxis natrattval”. cil. . pl). 97 y ss; Rosall)a (aumpra, "Il fantastico:

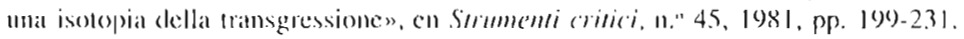

54.- Además de Rosilba (ampra, otros autores consideran gue lo fantástices se encuentra lambién en el lenguaje, como Noé Jitrik. que dice: "l o fantístico reside, antes que nada, en el lenguije; haly un modo de Iratalr la palabra yue favorece un cambio de plano, la aparición de una nueva dimensión refericla por contraste, a la dimensión de lo real. Peso ba palabra no liene ese poder en sí sino a partir de los actos o siluaciones que refiere. Lo lantástico se centra, entonces, en ciertos núcleos del relato y és allí donde tie-

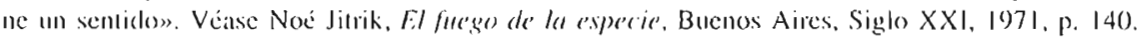


Queremos decir que en definitiva lo lantístico depende de criterios semánteos, pues éslos son ios (pue rigen la estructura de conjunto referencial, lamto la primigenia la (jue presenta las zonas de indeterminación como la completalia por el lector, que será lat de unn texto fintástico si presenta elementos infractores. rupturales, transgresores, que se incluyen palla dar una explicación a uno o vartios sucesos fue no la tienen. La incorporación de nuevos elementos tiene come linalidad dar una explicación a esal laguna discursiva, porque es indudable que el lector participa de la lectura, y este es un claro ejemplo de cómo lo hace. Parece obvio (pue el género fantástico se orienta muy clatamente hacia el receptors. (que tiene que percibir e interpretar exaclamente lo yue el productor fe commenica. con la dificultad añadiela de la verosimilitud parla textos fantásticos verosímiles.

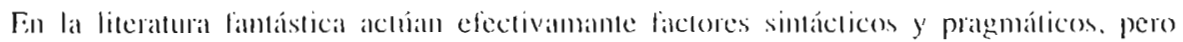
to hacen sobre los aspectos semínticos. (que end definitiva son les que. por suponer una transgeresión de las reglas del mundo comprírico, determinan lo fantístico. Lal "fantasticidad» si se nos permite el términe) raklicar en la relación yue el referente mantiene con lat realidad

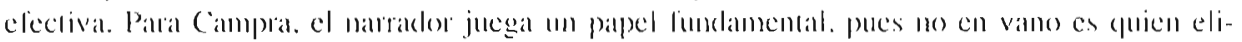

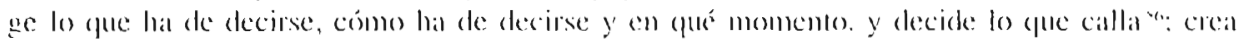

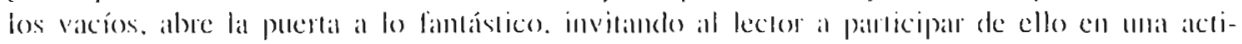

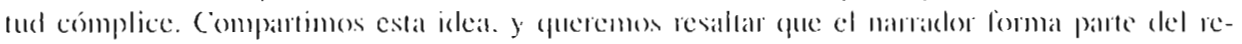

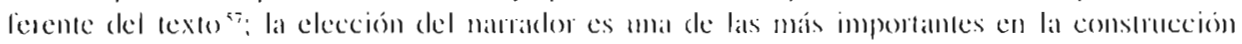
de la estructura de conjunto referencial, pues es la persona én guien delega el antor para conlarr su historiat.

Finamente, si la realidad es cambiante, lo son también sus reglas y su representación.

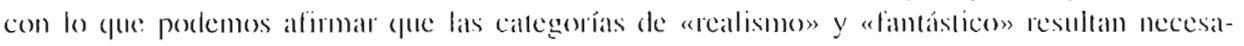
riamente históricas, dade (jue los sistemas convencionales son evidentemente tributarios de la

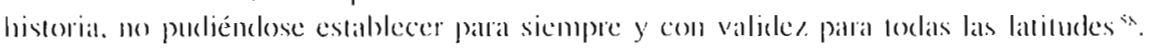

lil género fantástico es un género histórico. poryue depende del referente y de sur representación, que son cambiantes, históricos; depende de factores semámbicos. de ho representa(d), no de la representación. en la due predominan lictores sintácticos y verbales, mecanismos característicos de los llamados gémeros maturales.

\section{Verosimilitud y fantasía.}

Fin ta literatura fambística, es decir. en las obrats cuyal estructura de conjumto referencial responde a reglas pertenecientes a un modelo de mundo de lo fantástico verosímil o de lo fantástico inverosímil, la oblención de la verosimilitud es lambién un objetive (tét antor, alun-

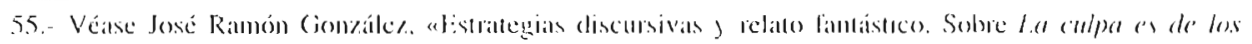
llavealeeras de Eilena (iarro», en l.a Tomre. V, 20. 1991, pp. 475-488.

56.- Rosalbat (amprat, "Fantástico y sintixis narrativat". cil., pp. 105 y s.s.

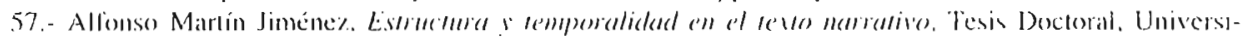
dad de Valladolid, 190)1.

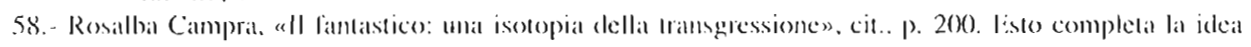
(e la polbe determinación y los cambiantes límites de las licciones de las (pue hablan A. 7.gon/elski. "()n differentialing lantastic liction: some supragenological distinclions in literature". en Poefics Todey, 5:2.

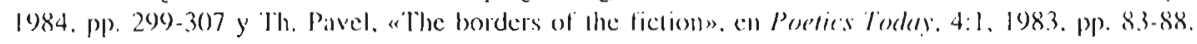


que ésta tiene un carácter distinto que en las obras pertenecientes a modelos de mundo de lo lïcional verosímil.

Todas las obras litcrarian deben ser verosímiles conforme a las leyes de su género, que

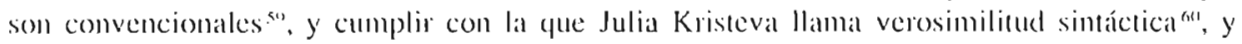
con las reglas del decoro; las oblas pertenecientes al macromodelo de mundo real son verosímiles por ser miméticals, y, como diece el principio fïlosófico, lo gue es evidente no necesita demostración. No ocurre así con lass obras del macromodelo de mundo fautástico: la verosimilitud hay que demostrarla, annque el autor no pretende siempre que la transgresión se muestre como real. Sin combargo, creemos que hay un conjunto de obras que responden a reglas de modelo de mundo fantástico verosímil, en lis que el autor tiene como uno de sus principates objetivos, previo e imprescindible a otros, la consecución de la verosimilitud, lo que conseguirá creando una apariencia de realidad, un electo de real ${ }^{61}$, superando la dificultad de que nos crean, obstáculo añadido para el escritor de este tipo de obrasos.

Benedetto (roce también ercia en la polémica sobere la verosimilitud. y nos aýnda a distinguir por una parte lo verosímil como «la colnerencia arlística de la representación. esto es. la plenitud, la eficacia, la efectiva presencia de ésla. (...) Un persomaje veresímil, un final verosímil de comedia, son, en realidad. personajes mal dibujados. finales contades, sucesos

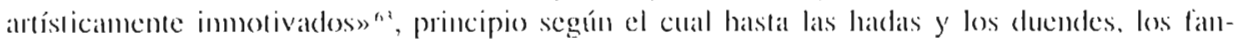
tasmais y los ogros han de tencr siempre verosimilitud; por otra parte lo verosímil es también "el carácter de credibilidad históricil». Io yue tiene que ver con la relación entre los seres, objetos, acciones, procesos e ideas de la estructuria de conjunto referencial y la realidad exterior. Lsta verosimilitud es inherente a las obras construidas de acuerelo con leyes pertenecienles a modelos de mundo de lo verdadero y de lo fiecional verosímil, que son miméticos, pero es un valor que el productor de obras construidas de acuerdo a leyes pertenecientes a modelos de mundo de lo fantástico verosímil hat de lograr parar que el lector las considere como lales y para cute se consiga el efecto pretendiclo. La productor de un texto construicto con leyes propias al modelo de mundo de to fantástico verosímil tiene como objetivo principal la creación de ese efecto de realidad, efecto yue ha de percibir el lector para que se dé la perrecta comunicación literaria. In el casso de las obras construidas de acuerdo a leyes propias del tipo de modelo de mundo de lo fantástico inverosímil, el productor ha de cuidar exclusivamente de la verosimilitud interna, de la coherencia artistica, ya cue el efecto que pretende en el lector puede provocarlo sin que los hechos que narra parezcan posibles, dables.

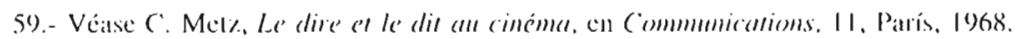

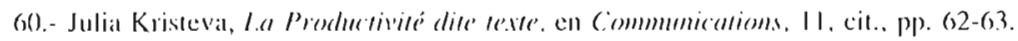

61.- Roland Bartles, líffer de réel, en Commmnications. II, cit.

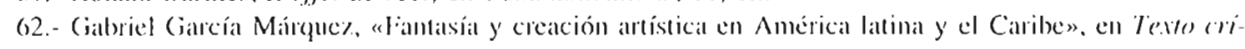
licos, n." 14, 1979. pp). 3-8.

6.3.- Benedelto Croce, Astética como ciemeia de la expresión y lingiästica géneral. Buenos Aires, Nueva Visión, 1969, p. 117. 